\title{
The Computer-Assisted Web Interview Method as Used in the National Study of ICT Use in Primary Healthcare in Poland - Reflections on a Case Study
}

\author{
Paweł Sowa ${ }^{1}$, Bartosz Pędziński ${ }^{1}$, Michalina Krzyżak ${ }^{1}$, \\ Dominik Maślach ${ }^{1}$, Sylwia Wójcik ${ }^{2}$, Andrzej Szpak ${ }^{1}$ \\ 1 Department of Public Health, Medical University of Bialystok, Poland \\ 2 Student of Public Health, Medical University of Bialystok, Poland
}

\begin{abstract}
The development and widespread use of ICT in society are reflected by the way research is designed and conducted. The Computer Assisted Web Interview method is becoming more attractive and is a frequently used method in health sciences. The National Study of ICT Use in Primary Healthcare in Poland was conducted using this method. The aim of this paper is to present the major advantages and disadvantages of web surveys. Technical aspects of methodology and important stages of the aforementioned study, as well as key elements for its procedure, are mentioned. The authors also provide reflections based on their analysis of this national study, conducted between January and April 2014.
\end{abstract}

\section{Introduction and Objectives}

The development and widespread use of ICT in society are reflected by the way research is designed and conducted. Increasingly, surveys are carried out via the Internet (online), resulting in a loss of direct contact with the respondent (Sobieszek, 2006).

The Computer Assisted Web Interview (CAWI) is a research method which is the result of the evolution of the following previously used popular methods: Paper and Pencil Interviews (PAPI) and Computer Assisted Telephone/Personal Interviews (CATI/CAPI). These methods had the advantage, as far as popularity was concerned, at the end of the twentieth century. However, with the increasing popularization of using the Internet, the CAWI is becoming a research tool with a large group of followers.

The CAWI method involves the creation of a research questionnaire, which is to be shown on the website in such way as to be available on- 
line for respondents to fill out (Mider, 2013). Questions and answers in the questionnaire are standardized and previously predefined (Fowler et al., 1990).

The literature often raises the problem of improper naming of the CAWI method (as an interview), which, as a modification of classical (PAPI, CATI) methods of questionnaire research, suggests the presence of an additional person conducting the interview, functioning as an intermediary between the respondent and the questionnaire. In fact, the CAWI is more of a survey study where respondents fill in a questionnaire without the involvement of the person conducting the study (Mider, 2013). This problem is directly reflected in the methodological standard questionnaire or interview (the difference in control of the research process).

Another problem with the CAWI method concerns selection of a research sample that would allow for the generalization of statistical results to the entire population (Bethlehem, 2009; Kraut et al., 2004). This seems to be difficult due to difficulty in determining the representativeness of the respondents.

The aim of this paper is to analyze a case study of the CAWI method, used in the National Study of ICT Use in Primary Healthcare, in order to observe advantages and disadvantages of the method and the possibility of its application in a similar type of research. The technical sides of the study, including each of its stages, have been analyzed. On this basis, conclusions that can be used for designing research with similar methods have been drawn.

\section{Materials and Methods}

The National Study of ICT Use in Primary Healthcare was conducted using the Computer-Assisted Web Interview method due to the fact that it was recommended by researchers carrying out similar studies in Europe (Dobrev et al., 2008). Using such a method seemed to be unnecessary with regard to sample size as well as the expectation of study completion within a short amount of time (less than 2 months). In order to minimize the disadvantages of the CAWI method, a pilot study was conducted. In addition, there were General Practitioner organizations invited to take part in the study by way of assistants informing their members on aim, schedule, and advantages of the study. Their role was also to promote the study among associated GP's, as well as to cooperate with authors while conducting the study in particular regions of Poland. 
The National Study of ICT Use in Primary Healthcare was carried out in three stages. The first order of business was to complete the database a list of primary healthcare providers involving e-mail addresses, GP association membership, and location. The second step was to create a survey questionnaire that would properly cover major issues concerning attitudes, barriers to ICT implementation, and the specifics of electronic medical documentation. The third step was to set a time schedule for each stage, taking into account the information campaign (encouraging organizations to cooperate), and to conduct and coordinate the study (including the first mailing and week-after reminder mailing).

The database was created using publicly available inventories of healthcare providers, namely the National Health Fund database and Registry of Healthcare Providers (http://rpwdl.csioz.gov.pl/). Deficiencies in the database were replenished by sending queries to the participating organizations as well as through the private work of members of the research team.

The questionnaire used for the study was prepared using e-health indicators proposed by Dobrev et al. (2008) as well as feedback of the pilot study carried out in the Podlaskie region. It included 52 closed questions with multichotomous answers, but the number of questions depended on the level of electronic medical documentation adoption in particular healthcare settings. The survey questionnaire for online interviews was design with Google Form. Each healthcare unit providing primary care received an email with an invitation to participate in the study, individual ID code, and hyperlink to the web-survey. The ID code had to be entered into the questionnaire at its beginning. This was required in order to prohibit any one respondent from answering multiple times. To ensure better randomization of survey respondents in a particular primary care unit, information was sent that the interviewed person should be either the doctor or manager whose surname came first in the alphabet. After completion of the survey, answers were sent directly to the electronic database (google drive). For the purposes of this study, as well as further R\&D projects in the field of e-health, a dedicated website - www.ehealth.edu.pl - featuring the questionnaire and additional information, has been created.

The survey questionnaire was sent to all primary healthcare providers in Poland (General Practitioners and other healthcare units) who had a relevant contract (GP service) with the National Health Fund (as of $18^{\text {th }}$ January 2014). The database was divided into "mailing groups", two regions for each week. Seven days after the first mailing, reminder e-mails were sent to those units that did not respond. More details on the timeline of the study are presented in Figure 1. 


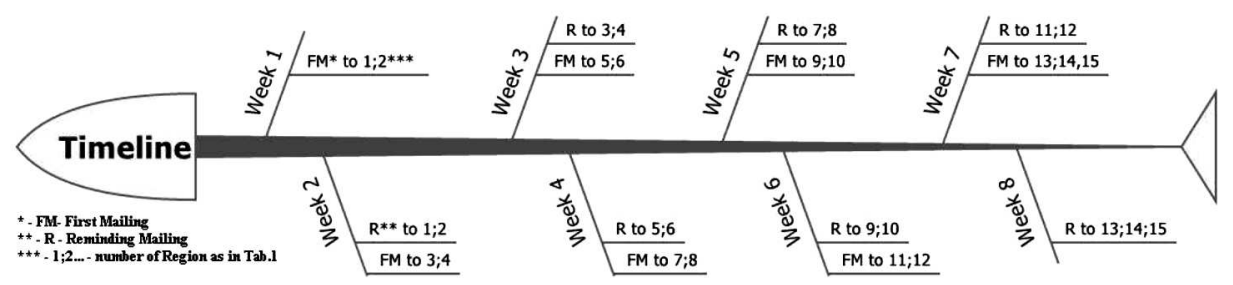

Figure 1. Timeline of the National Study of ICT Use in Primary Healthcare

Preparation for the study also included an information campaign supported by primary healthcare associations. It consisted of announcements during branch meetings, placing announcements in a "news" bookmark on their websites, and sending special e-mails. Such support was given by the following organizations: Federation of Employers in Health Care - "Porozumienie Zielonogorskie", the Polish Society of Family Medicine, and the College of Family Physicians in Poland.

\section{Results}

The main goal of this paper is to find advantages and disadvantages of web-surveying methodology for future use in the field of public health. From that vantage point, the number of responses shall be analyzed regarding technical aspects of the study.

The pilot study was conducted in the Podlaskie region between April and May 2013, while the further 15 regions were studied between January and April 2014. The total number of responses obtained during that time was 1,029 but 16 of them were rejected because of their quality deficiencies ("empty answers" etc.). Finally, the answers of 1,013 respondents were taken into account in the statistical analysis. This accounts for $16.34 \%$ of all Polish primary healthcare providers that have a contract with the National Health Fund.

The complete study population, the primary health care units that had a contract with the NHF, was 5,961 (excluding the Podlaskie region, where the pilot study was conducted). An e-mail with a link to the survey was successfully sent to 5,115 units. This e-mail was not received by $14.19 \%$ of primary care providers for one of the following reasons: the recipient's mailbox was overloaded, the recipient's settings could block unknown addresses, or there were deficiencies in the quality of public institutions' databases. Taking into account effectively sent e-mails, the response rate 
in the 15 Polish regions was $17.73 \%$ (15.22\% of all that had a contract with the NHF). The highest response rate was achieved in Pomorskie $32.26 \%$ for an effective mailing (26.94\% of all primary care providers), and Lubuskie $29.61 \%$ (23.81\%). The lowest rate was obtained in Wielkopolskie, where only a $9.77 \%(7.32 \%)$ response rate was achieved. The reason for these discrepancies seems to be the effectiveness of the information campaign supported especially by the Federation of Employers in Health Care, "Porozumienie Zielonogorskie". The regions with the highest rate returns were characterized by high interest in the study. Cooperating organizations encouraged frequent contact with the research team in order to better coordinate the research process. However, in the regions of Wielkopolskie and Zachodniopomorskie, these organizations are functioning to a limited extent (particularly the "Porozumienie Zielonogorskie"). Table 1 presents the return rates as well as - in the first column - the order in which the study was conducted.

Table 1. Responses obtained in the National Study of ICT Use in Primary Healthcare in Poland

\begin{tabular}{|r|l|r|r|r|r|r|}
\hline $\mathrm{Nb}$ & \multicolumn{1}{|c|}{ Region } & $\begin{array}{c}\text { GP Units } \\
\text { contracted } \\
\text { by NHF* } \\
{[\mathrm{A}]}\end{array}$ & $\begin{array}{c}\text { E-mail } \\
\text { successfully } \\
\text { sent } \\
{[\mathrm{B}]}\end{array}$ & $\begin{array}{c}\text { Answers } \\
{[\mathrm{C}]}\end{array}$ & $\%$ C/B & $\%$ C/A \\
\hline 1 & Lubelskie & 430 & 395 & 81 & $20.51 \%$ & $18.84 \%$ \\
\hline 2 & Małopolskie & 467 & 426 & 76 & $17.84 \%$ & $16.27 \%$ \\
\hline 3 & Swiętokrzyskie & 671 & 602 & 117 & $19.44 \%$ & $17.44 \%$ \\
\hline 4 & Mazowieckie & 275 & 236 & 43 & $18.22 \%$ & $15.64 \%$ \\
\hline 5 & Warmińsko-mazurskie & 446 & 412 & 65 & $15.78 \%$ & $14.57 \%$ \\
\hline 6 & Lódzkie & 748 & 673 & 103 & $15.30 \%$ & $13.77 \%$ \\
\hline 7 & Sląskie & 297 & 248 & 80 & $32.26 \%$ & $26.94 \%$ \\
\hline 8 & Pomorskie & 305 & 273 & 41 & $15.02 \%$ & $13.44 \%$ \\
\hline 9 & Kujawsko-pomorskie & 495 & 434 & 74 & $17.05 \%$ & $14.95 \%$ \\
\hline 10 & Dolnośląskie & 189 & 152 & 45 & $29.61 \%$ & $23.81 \%$ \\
\hline 11 & Lubuskie & 185 & 130 & 28 & $21.54 \%$ & $15.14 \%$ \\
\hline 12 & Opolskie & 341 & 284 & 57 & $20.07 \%$ & $16.72 \%$ \\
\hline 13 & Podkarpackie & 300 & 226 & 26 & $11.50 \%$ & $8.67 \%$ \\
\hline 14 & Zachodnio-pomorskie & 628 & 471 & 46 & $9.77 \%$ & $7.32 \%$ \\
\hline 15 & Wielkopolskie & 238 & 238 & 104 & $43.65 \%$ & $43.65 \%$ \\
\hline 16 & Podlaskie** & 6199 & 5353 & 1013 & $18.92 \%$ & $16.34 \%$ \\
\hline & TOTAL & & & & & \\
\hline
\end{tabular}

* NHF - National Health Fund

** In Podlaskie the pilot study was conducted using a mix of CAWI and CATI methods 
Comparing the effectiveness of the first mailing, and the reminders that followed 7 days after, it was observed that $52 \%$ (a total of 470 ) of the responses were obtained after the initial mailing, while $48 \%$ (439) after the reminders. The response rate in the reminder phase was higher than in the first mailing phase in the following regions: Pomorskie, Świętokrzyskie, Podkarpackie and (slightly) Wielkopolskie. In these regions, thanks to the positive cooperation with related organizations, additional informational activities (i.e. internal mailing in the organizations) were performed before and during the time reminders were sent. Because of the will to carry out the study in a short time across the whole country, as well as the need to maintain an identical standard for all studied regions, further attempts to send reminders were abandoned. Figure 2 presents, in detail, the distribution of responses obtained after the first mailing and further reminders. As it has been mentioned, reminder e-mails were sent 7 days after the first communication and only in cases of lack of response.

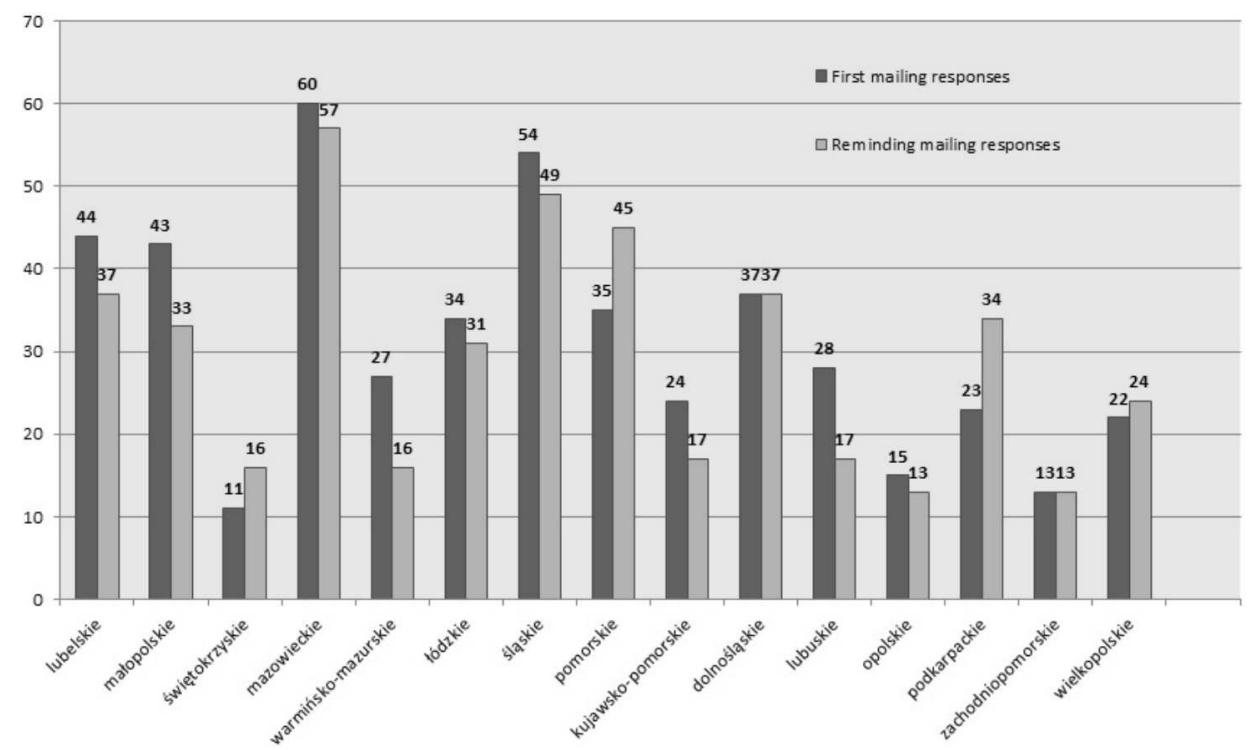

Figure 2. Comparison of responses: First mailing vs Reminders

The Podlaskie region, after participating in the pilot study, was not included in the national one due to the short time since former contact with respondents and the fear that they would be reluctant to repeat answering similar questions. However, regarding some issues, the results of the pilot will be taken into account in the overall statistical analysis. 


\section{Discussion}

Placing the Computer Assisted Web Interview method among the survey questionnaire and interview, both advantages and disadvantages should be noted. Firstly, in terms of the duration of study - a CAWI may contain more questions than a traditional questionnaire survey, but less than an interview. The presence of the interviewer, who can establish a social relationship with the respondent and provide a motivating factor (as in the PAPI or CATI methods), seems relevant here. Questionnaire surveys generally take less time (collecting answers from one respondent) than interviews, which should be treated as their advantage. The advantages of the CAWI, including the ability to gather answers in a short amount of time, creation of a database of the respondents, and the ability to make technical corrections in the questionnaire, need to be considered. Secondly, such studies are much cheaper than the conventional, previously mentioned forms (Kwak et al., 2002). The ability to persuade the respondent to answer the questionnaire has the advantage that a low number of faulty surveys are returned (omitting questions does not allow one to go to the next part of the questionnaire, and an improperly filled questionnaire cannot be sent). The absence of an interviewer may also be seen as an advantage, especially for sensitive topics about which questions can be a source of discomfort to the respondent. In addition, this form of study gives the surveyed person the impression of greater anonymity. As an intermediary in the CAWI study (as in the PAPI or CATI methods) additional comments to individual questions, which are often a small line of text placed immediately before or after a key question, are used. They complement the knowledge of the respondent and resolve possible ambiguity arising in the process of answering.

Another issue to consider is the so-called "mode effect". It concerns a respondent's mood - the ability to give objective answers. Some studies have observed that respondents could rate their health status differently in a web or traditional postal survey (Carini et al., 2003; de Vries et al., 2005; van Campen et al., 1998). Naturally, the only possible method to check if the mode effect influenced the results is to compare two study methods.

The response rate obtained in our study is at the average level. Studies using the CAWI method show that such rates may differ. In some cases, very promising values of even $70 \%$ can be observed (Leece et al., 2004). Other authors claim that there is no significant difference in response rate between Internet and paper-and-pencil versions of questionnaires (Ekman et al., 2006; Pealer et al., 2001; Ritter et al., 2004). All of the previously mentioned stud- 
ies included reminder procedures as key elements influencing response ratio. This statement is disputed by the study of Nulty (2008), which presents the opinion that face-to-face administration results in higher response rates, but the question of whether online surveys would reach similar levels if they were carried out using a face-to-face model remains without answer.

Missing data (the problem of "nonresponse"), difficulties in sample randomization, possible bias, and limitation to those who are Internet users are the major disadvantages of the CAWI method (Bosnjak et al., 2001; Sills et al., 2002). To avoid these disadvantages, such studies should be planned precisely and divided into separate stages. It seems that a reminder procedure, information campaign, and involvement of a variety of organizations are crucial to the effectiveness of this type of study. Web surveys have many positives, including short time needed for research, excellent control over the data collection process, flexibility of questionnaire (ability to react to respondents' concerns), low cost of the study, and geographic spread of respondents (Barbu et al., 2011).

\section{Conclusions}

1. There are many advantages to using the CAWI method when carrying out studies in the field of public health, including: short time needed for research, excellent control over the data collection process, flexibility of the questionnaire (ability to react to respondents' concerns), the low cost of the study, and geographic spread of respondents.

2. The negative aspects of the method include: limitations for respondents (only Internet users can participate), deficiencies in public registers of healthcare providers (necessary for preparing the study database), inactive respondent e-mail addresses, and low response rate.

3 . The reminder procedure and the support of primary care representatives (organizations, institutions) in the information campaign played an important role as the National Study of ICT Use in Primary Healthcare in Poland was conducted.

\section{R E F E R E N C E S}

Barbu, A., \& Isaic-Maniu, A. (2011). Data collection in Romanian market research: a comparison between prices of PAPI, CATI and CAWI. Management \& Marketing Challenges for the Knowledge Society, 6(3), 349-364. 
Bethlehem, J. (2009). Can We Make Official Statistics with Self-Selection Web Surveys? Data Collection: Challenges, Achievements and New Directions. Statistics Canada's International Symposium Series: Proceedings. Component of Statistics Canada Catalogue no. 11-522-X. Retrieved from http://www. statcan.gc.ca/pub/11-522-x/2008000/article/10989-eng.pdf

Bosnjak, M., \& Tuten, T. L. (2001). Classifying Response Behaviors in Webbased Surveys. Journal of Computer-Mediated Communication, 6(3), 0. DOI: 10.1111/j.1083-6101.2001.tb00124.x

Carini, R. M., Hayek, J. C., Kuh, G. D., Kennedy, J. M., \& Ouimet, J. A. (2003). College student responses to web and paper surveys: does mode matter? Res Higher Educ, 44(1), 1-19.

de Vries, H., Elliott, M. N., Hepner, K. A., Keller, S. D., \& Hays, R. D. (2005). Equivalence of mail and telephone responses to the CAHPS Hospital Survey. Health Serv Res, 40(6), 2120-2139.

Dobrev, A., Haesner, M., \& Husing, T. (2008). Benchmarking ICT use among General Practitioners in Europe - final report. Retrieved from Rede Comum de Conhecimento website: http://www.rcc.gov.pt/SiteCollectionDocuments/ ICT_Europe_final_report08.pdf

Ekman, A., Dickman, P. W., Klint, A., Weiderpass, E., \& Litton, J. E. (2006). Feasibility of using web-based questionnaires in large population-based epidemiological studies. Eur J Epidemiol, 21(2), 103-111.

Fowler, F. J., \& Magnione, T. W. (1990). Standardized Survey Interviewing: Minimizing Interviewer-Related Error. Newbury Park, CA: Sage.

Kraut, R., Olson, J., Banaji, M., Bruckman, A., Cohen, J., \& Couper, M. (2004). Psychological research online: Report of board of scientific affairs' advisory group on the conduct of research on the internet. American Psychologist, $59(2), 105-117$.

Kwak, N., \& Radler, R. (2002). A comparison between mail and web surveys: response pattern, respondent profile, and data quality. J Off Stat, 18(2), $257-273$.

Leece, P., Bhandari, M., Sprague, S., Swiontkowski, M. F., Schemitsch, E. H., \& Tornetta, P. (2004). Internet versus mailed questionnaires: a controlled comparison. J Med Internet Res, 6(4), e39.

Mider, D. (2013). Dylematy metodologiczne badań kultury politycznej w Internecie. Przeglad Politologiczny, 2, 23-24.

Nulty, D. D. (2008). The adequacy of response rates to online and paper surveys: what can be done? Assessment \& Evaluation in Higher Education, 33(3), $301-314$.

Pealer, L. N., Weiler, R. M., Pigg, R. M., Miller, D., \& Dorman, S. M. (2001). The feasibility of a web-based surveillance system to collect health risk behavior data from college students. Health Educ Behav, 28(5), 547-559.

Ritter, P., Lorig, K., Laurent, D., \& Matthews, K. (2004). Internet versus mailed questionnaires: a randomized comparison. J Med Internet Res, 6(3), e29. 
Sills, S. J., \& Song, C. Y. (2002). Innovations in survey research: an application of web-based surveys. Soc Sci Comput Rev, 20(1), 22-30.

Sobieszek, K. (2006). Problem błędu braku odpowiedzi w badaniach internetowych. In W. Jonak, P. Mazurek, M. Olcoń, A. Przybylska, A. Tarkowski, \& J. M. Zając (Eds.). Re: Internet spoteczne aspekty medium. Polskie konteksty $i$ interpretacje (pp. 365-394). Warszawa, Polska: WAiP.

van Campen, C., Sixma, H., Kerssens, J. J., \& Peters, L. (1998). Comparisons of the costs and quality of patient data collection by mail versus telephone versus in-person interviews. Eur J Public Health, 8(1), 66-70. 